\title{
CURVAS DE SECAGEM DE SEMENTES DE MILHO UTILIZANDO O MÉTODO INTERMITENTE
}

\author{
F.A. VILLELA ${ }^{1} \&$ W.R. da SILVA ${ }^{2}$
}

RESUMO: O presente trabalho teve por objetivo determinar as curvas de secagem de sementes de milho, para diferentes temperaturas do ar, durante a secagem intermitente. Foram utilizados três lotes de sementes de milho do hibrido duplo AG-162 e um secador marca D'Andréa, modelo D-200. As temperaturas do ar de secagem empregadas foram de 70, 80 e $90^{\circ} \mathrm{C}$. As seguintes determinaçōes foram realizadas: teor de água das sementes, temperatura do ar de secagem, temperaturas da massa de sementes na câmara de secagem e na saída do secador, umidade relativa do ar e temperatura do ar ambiente. Considerando temperaturas do ar de secagem de 70, 80 e $90^{\circ} \mathrm{C}$ e reduções do teor de água de $16,5 \%$ para $13,0 \%$, os resultados permitem as seguintes conclusões: a) as curvas de secagem de sementes de milho, utilizando o método intermitente, podem ser representadas por funções lineares. b) o aumento da velocidade de secagem e a redução do tempo total de exposição das sementes ao ar aquecido podem ser obtidos pela elevação da temperatura do ar de secagem.

Descritores: secagem, curvas de secagem, milho.

\section{DRYING CURVE OF CORN SEEDS BY THE INTERMITTENT METIIOD}

ABSTRACT: The objective of this work was the determination of the drying curve of corn seeds for different air temperatures during the intermittent drying process. Three lots of double hybrid AG-162 corn seeds and a D'Andrea dryer, model D-200, were utilized. Air temperatures of 70,80 and $90^{\circ} \mathrm{C}$, were used during the drying process. The following determinations were made: seed moisture content, air temperature at drying, seed temperature in drying roon and drier outled, air relative humidity and environment temperature. Considering the temperature of the drying processes at 70,80 and $90^{\circ} \mathrm{C}$ and the reduction of moisture content from $16,5 \%$ to $13,0 \%$, the following conclusions were obtained: a) corn seed drying curves in the intermittent drying process can be represented by linear functions; b) the increase of the drying speed and the reduction of total time of seed exposition to hot air can be achieved by temperature elevation of drying air.

Key Words: drying, drying curve, corn.

\section{INTRODUÇÃO}

A tecnologia recomendada para a produção de sementes sugere, de maneira generalizada, colheitas em momentos que precedem o ponto em que as sementes se encontram com teores de água compatíveis com a sua conservação no armazenamento. Com isso, a secagem artificial demanda conhecimentos de sua ação sobre a qualidade final do produto, além de exigir o domínio operacional relacionado com o seu rendimento.

O processo de secagem visa a retirada parcial da água da semente, através da transferência simultânea de calor do ar para a semente e de massa, por meio do fluxo do vapor d'água, da semente para o ar (FOUST et al., 1982).

A secagem de sementes, mediante ventilação forçada de ar promove, essencialmente, dois processos simultâneos: a) transferência de água da superfície da semente para o ar circundante, que ocorre quando a pressão parcial de vapor na superfície da semente é maior do que a no ar circundante; b) movimento de água do interior para a superfícic da semente, em virtude do gradiente de potencial hídrico entre as duas regiões.

Em sementes, LASSERAN (1978) sugeriu que o fluxo de água do interior para a superfície, durante a

\footnotetext{
${ }^{1}$ Departamento de Física da Universidade Federal de Pelotas. 96100-PELOTAS,RS

${ }^{2}$ Departamento de Agricultura da Escola Superior de Agricultura "Luiz de Queiroz" - Universidade de São Paulo. 13418-900 - PIRACICABA-SP. (Bolsista do CNPq).
} 
secagem, é ocasionado por um derramamento hidrodinâmico sob a ação da pressão total interna e/ou por um processo de difusão resultante de gradientes internos de temperatura e teor de água ou de um gradiente de pressão osmótica.

O processo de secagem de um produto, sob condições constantes de temperatura, umidade relativa e velocidade do ar, pode ser dividido em um período de velocidade constante e outro de velocidade decrescente.

Durante o período de velocidade constante, a temperatura do produto se mantém igual à do ar de secagem saturado e as transferências de calor e massa se compensam. O mecanismo interno de fluxo de água não afeta a velocidade de secagem porque a taxa de deslocamento interna da água para a superfície do produto é igual ou maior do que a máxima taxa de remoção de vapor d'água pelo ar, sendo evaporada apenas a água livre (HALL, 1980; FOUST et al., 1982; SODHA et al., 1987).

As sementes, em geral, apresentam o período de secagem a velocidade constante muito curto, ou inexistente, porque, nas condições operacionais de secagem, as resistências às transferências de água encontram-se essencialmente no seu interior, tornando a taxa de evaporação superficial acentuadamente superior à taxa de reposição de água do interior para a superfície (KREYGER, 1973; BROOKER et al., 1974; LASSERAN, 1978).

No período de velocidade decrescente de secagem, a taxa de transporte interno de água é menor do que a taxa de evaporação; desta forma a transferência de calor do ar para as sementes não é compensada pela transferência do vapor de água e, em consequência, a temperatura da semente aumenta, tendendo à temperatura do ar de secagem (HALL, 1980; FOUST et al., 1982).

O período de velocidade decrescente pode ser dividido em dois estádios(FORTES, 1978; HALL, 1980; FOUST et al., 1982):

a) estádio de superfície insaturada, quando não há continuidade de evaporação em toda a superfície do produto, decrescendo a taxa total de evaporação superficial. $\mathrm{O}$ transporte de água no interior do produto ocorre na fase líquida devido ao gradiente de sua concentração, denominado difusão líquida. Pode ocorrer movimento de vapor de água, motivado pelo gradiente de temperatura, denominado difusão de vapor.

b) estádio de controle interno de umidade, quando a região de vaporização situa-se no interior do produto e a velocidade de secagem é determinada pelo movimento interno de água. Neste estádio, a velocidade de secagem decresce rapidamente e a água situada nos capilares menores pode se mover ao longo das paredes dos capilares e/ou por evaporações e condensações sucessivas.

Os métodos de secagem artificial, quanto ao fluxo das sementes no secador, podem ser classificados em duas categorias (KREYGER, 1973; BROOKER et al., 1974; TOLEDO \& MARCOS FILHO, 1977): a) secagem estacionária: consiste em forçar um fluxo de ar através da massa de sementes que permanece em repouso; b) secagem de fluxo contínuo : consiste em submeter as sementes a uma corrente de ar, enquanto estas fluem continuamente através do secador.

Considerando a forma de atuação do ar aquecido, a secagem artificial pode ser dividida em dois tipos (BROOKER et al., 1974; TOLEDO \& MARCOS FILHO, 1977): a) secagem contínua: as sementes ficam permanentemente sob a ação do ar aquecido, até o seu teor de água atingir o valor desejado; b) secagem intermitente: as sementes são submetidas à ação do ar aquecido durante intervalos regulares de tempo, intercalados por períodos sem aquecimento, denominados períodos de repouso. A intermitência permite que ocorra o transporte de água do interior para a superfície da semente durante o período de repouso.

Edholm' verificou que na secagem intermitente de sementes empregando uma série de curtos períodos sob a ação do ar aquecido, intercalados por longos períodos de repouso, a quantidade de água removida por unidade de tempo é consideravelmente maior do que na secagem contínua, porque o limite máximo da velocidade de secagem, após a remoção da água da camada superficial da semente, é a velocidade de transporte da água do interior para a superfície.

As sementes mais úmidas são mais sensíveis aos danos térmicos; por isso quanto mais elevado o teor de água, menor deve ser a temperatura empregada na secagem (HARRINGTON, 1972). Entretanto, segundo Washko ${ }^{2}$, o dano térmico ocorre durante a última fase da secagem, quando o teor de água da semente e a velocidade de secagem são menores devido à redução da velocidade de evaporação e à elevação da temperatura da semente.

A velocidade de secagem de sementes de milho em espiga é influenciada pela espessura e permeabilidade do pericarpo (PURDY \& CRANE, 1967), genótipo, maturidade da semente, teor de água da semente na colheita, diâmetro da espiga (CROSS, 1985) e espessura da camada de aleurona (TOTH \& SULLER, 1987).

As curvas de secagem de sementes de azevém (Lolium multiflorum L.), em secador intermitente e temperatura do ar de $50^{\circ} \mathrm{C}$ e $80^{\circ} \mathrm{C}$, se ajustam a 
equações de primeiro grau e as velocidades de secagem alcançam, respectivamente, $1,4 \%$ e $1,0 \% / \mathrm{h}$ (BOUNOUS, 1986).

$\mathrm{Na}$ secagem de sementes de arroz em secador intermitente à temperatura do ar de $70^{\circ} \mathrm{C}$, variando o fluxo de ar, o teor de água inicial das sementes e o tempo de exposição ao ar aquecido, LUZ (1986) constatou que existe uma relação linear entre a redução do teor de água e o tempo de secagem e que as velocidades de secagem alcançam $1,6 \% / \mathrm{h}$ a $2,0 \% / \mathrm{h}$.

Em secadores intermitentes são empregados, em geral, elevados fluxos de ar e altas temperaturas do ar de secagem, possibilitando, desta forma, uma alta capacidade de secagem. Além disso, as sementes atingem temperaturas inferiores às do ar aquecido, o que vem contribuir de forma considerável para o emprego destes secadores na indústria de sementes.

A caracterização da secagem intermitente, quanto às curvas de secagem e à velocidade de secagem, possibilita a devida difusão de sua tecnologia.

A literatura tem se mostrado escassa em informações sobre a secagem de sementes, especialmente no que se refere à sua operacionalização. Dessa forma, o presente trabalho objetivou determinar as curvas de secagem de sementes de milho, para diferentes temperaturas do ar, durante a secagem intermitente.

\section{MATERIAL E MÉTODOS}

O presente trabalho foi realizado na Unidade de Beneficiamento (Santa Cruz das Palmeiras-SP) da empresa Sementes Agroceres S.A. e no Laboratório de Análise de Sementes do Departamento de Agricultura da Escola Superior de Agricultura "Luiz de Queiroz" (Piracicaba-SP).

Foram utilizadas sementes de milho, do híbrido duplo AG-162, de três lotes (A, B e C) que apresentavam teores de água iniciais, respectivamente iguais a $16,5 \%, 15,8 \%$ e $15,9 \%$.

O sistema de secagem utilizado foi o de um secador de fluxo contínuo, adaptado para operar na forma intermitente, da marca D'Andréa, modelo D-200, equipado com uma fornalha de calor irradiado e um elevador duplo de caçambas. A adaptação consistiu do aumento da capacidade da câmara de respouso de $4 \mathrm{~m}^{3}$ para $16 \mathrm{~m}^{3}$. O secador apresentava as seguintes características adicionais:

- Capacidade estática total: $36 \mathrm{~m}^{3}$

- Capacidade da câmara de secagem: $14 \mathrm{~m}^{3}$
- Capacidade da câmara de resfriamento: $6 \mathrm{~m}^{3}$ Operacionalmente, o equipamento foi regulado para atender o seguinte esquema de trabalho:

- fluxo de ar na câmara de secagem: $300 \mathrm{~m}^{3} / \mathrm{min}$.

- tempo de exposição das sementes ao ar aquecido por ciclo no sistema de secagem: $35 \mathrm{~min}$.

- período de equalização: $55 \mathrm{~min}$.

- relação aproximada de intermitência: 1:1,6

- tempo de descarga: $90 \mathrm{~min}$.

Os lotes A, B e C foram submetidos a secagem intermitente, empregando ar de secagem a temperaturas de $70^{\circ} \mathrm{C}, 80^{\circ} \mathrm{C}$ e $90^{\circ} \mathrm{C}$, respectivamente.

Cabe ressaltar que as temperaturas do ar utilizadas na secagem de sementes de milho em secador intermitente, em geral, não excedem $70^{\circ} \mathrm{C}$ e sua elevação poderia reduzir o tempo de secagem.

Durante o processo de secagem, 30 minutos após o início da secagem e em intervalos regulares de 30 minutos foram retiradas quatro amostras e acondicionadas em recipientes à prova de vapor d'água (lata vedada), completamente cheios, para a posterior determinação do teor de água das sementes, em laboratório.

Concomitantemente, as seguintes determinações foram realizadas:

a) Temperatura do ar de secagem: determinada através de um termômetro analógico, localizado no duto da entrada do ar aquecido no secador.

b) Temperatura da massa de sementes na câmara de secagem: determinada através de um termômetro analógico, localizado na parte inferior da câmara de secagem do secador.

c) Temperatura da massa de sementes na saida do secador: amostras foram coletadas na extremidade posterior da calha vibratória da descarga do secador e colocadas em recipientes semi-adiabáticos (caixa de isopor), sendo a temperatura medida por um termômetro de bulbo, acoplado perpendicularmente à tampa do recipiente, mantido na massa de sementes por um período de 2 minutos.

d) Umidade relativa do ar e temperatura ambiental: determinadas através de um psicrômetro, instalado nas imediações do ponto de coleta do ar pelo secador.

A determinação do teor de água das sementes foi realizada em estufa elétrica de desidratação, sem ventilação forçada, utilizando-se o método de estufa a $105^{\circ} \mathrm{C}+-3^{\circ} \mathrm{C}$, durante 24 horas, conforme prescrição das Regras para Análise de Sementes (BRASIL, 
Ministerio da Agricultura, 1980). Foram utilizadas duas amostras de $30 \mathrm{~g}$ de sementes cada uma e o teor de água foi expresso em porcentagem em base úmida.

As curvas de secagem foram determinadas através do ajustamento de curvas de regressão polinomial, relacionando-se o comportamento do teor de água das sementes e o tempo decorrido durante $o$ processo de secagem.

\section{RESULTADOS E DISCUSSÃO}

O acompanhamento do teor de água das sementes, durante a secagem, permitiu a determinação da curva de secagem (curva representativa da variação do teor de água da semente em função do tempo de secagem) e, desta forma, estimou a velocidade de secagem (redução do teor de água das sementes por unidade de tempo).

A Tabela 1 mostra que a temperatura média do ar ambiente atingiu $22,7^{\circ} \mathrm{C}$, quando a temperatura média do ar de secagem alcançou $70^{\circ} \mathrm{C}$. Desta forma, - aquecimento do ar para a realização da secagem demandou a elevação média de $47^{\circ} \mathrm{C}$, na temperatura do ar ambiente. Esta alteração, aplicada em gráfico psicrométrico, para pressão atmosférica de $760 \mathrm{~mm}$ de mercúrio (LASSERAN, 1978) considerando a umidade relativa do ar inicial média de $69 \%$, permitiu concluir que 0 ar aquecido passou a apresentar a umidade relativa de $7 \%$.

As temperaturas da massa de sementes na câmara de secagem e na saída do secador atingiram, respectivamente, 35 e $31^{\circ} \mathrm{C}$, após 150 minutos de secagem, mantendo-se, a partir daí, praticamente invariáveis em função do tempo, até o final do processo.

A relação entre a redução do teor de água das sementes e o tempo de secagem foi representada por uma equação de primeiro grau, capaz de explicar $94,35 \%$ da variação (Figura 1). Entre os teores de água de 16,5 e $13,2 \%$, a velocidade de secagem permaneceu constante em $0,52 \% / \mathrm{h}$.

Quando a temperatura média do ar ambiente foi de $24,6 \%$, a temperatura média do ar de secagem chegou a $80^{\circ} \mathrm{C}$ (Tabela 2). A umidade relativa do ar de secagem atingiu, conforme gráfico psicrométrico (LASSERAN, 1978), o valor de 5\%, determinado pelo acréscimo de $55^{\circ} \mathrm{C}$ na temperatura do ar ambiente, cuja umidade relativa média era de $72 \%$.

A temperatura da massa de sementes na câmara de secagem estabilizou-se em $39^{\circ} \mathrm{C} \mathrm{e}$, na saída do secador, em $32^{\circ} \mathrm{C}$, decorridos 150 minutos de secagem, sofrendo, assim, uma redução de $7^{\circ} \mathrm{C}$ ao atravessar a câmara de resfriamento.

$\mathrm{Na}$ Figura 2 observa-se que o teor de água das sementes decresceu de forma linear com o tempo, no decorrer da secagem à temperatura do ar de $80^{\circ} \mathrm{C}$, sendo que a função linear tem a possibilidade de justificar $93,7 \%$ da variação. A diminuição do teor de água das sementes por unidade de tempo manteve-se invariável em 0,66\%/h, para teores entre 15,8 e 13,1\%.

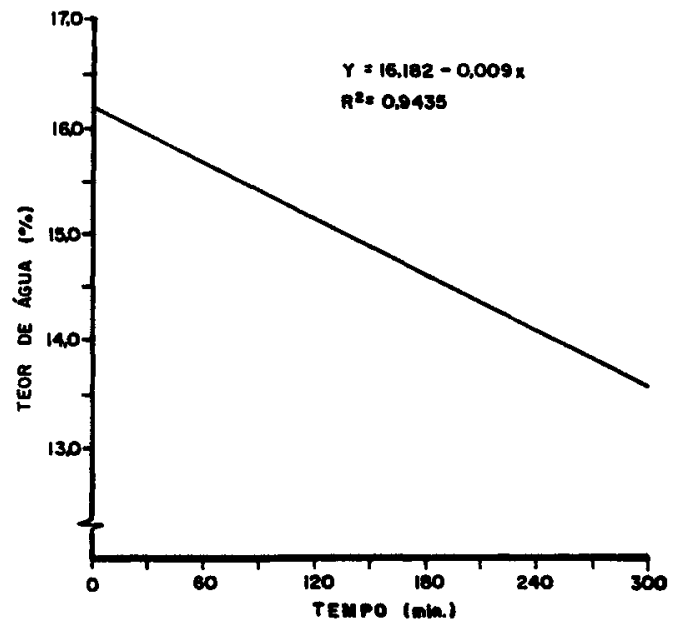

Figura 1 - Curva de secagem representando o comportamento do teor de água das sementes de milho em função do tempo. Secagem a temperatura do ar de $70^{\circ} \mathrm{C}$.

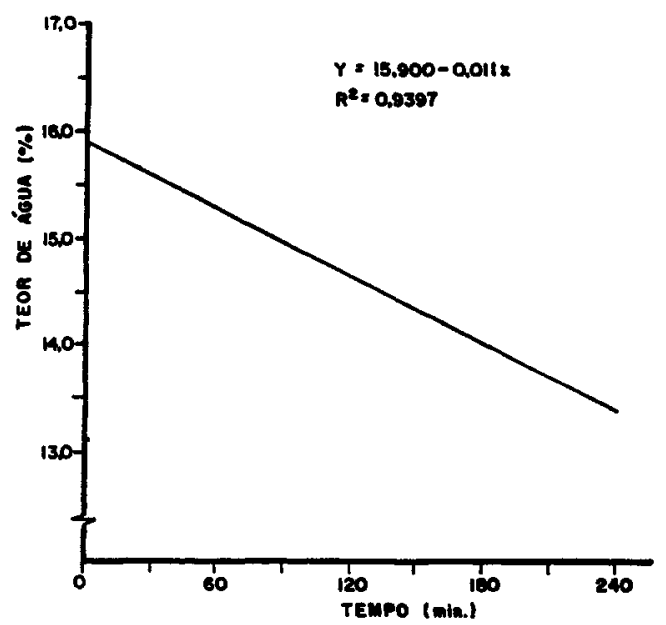

Figura 2 - Curva de secagem representando o comportamento do teor de água das sementes de milho em função do tempo. Secagem a temperatura do ar de $80^{\circ} \mathrm{C}$. 
Tabela 1 - Dados referentes às determinações realizadas durante a secagem das sementes de milho empregando ar de secagem à temperatura de $70^{\circ} \mathrm{C}$.

\begin{tabular}{|c|c|c|c|c|c|c|}
\hline \multirow{3}{*}{$\begin{array}{c}\text { Tempo de } \\
\text { Secrgem }\end{array}$} & \multicolumn{2}{|c|}{ Ambiente } & \multirow{3}{*}{$\begin{array}{c}\text { Temp. do } \\
\text { ar de } \\
\text { secagem }\end{array}$} & \multirow{2}{*}{\multicolumn{2}{|c|}{$\frac{\text { Temperatura de sementes }}{\text { Câmara Secagem Saída Secador }}$}} & \multirow{3}{*}{$\begin{array}{r}\text { Teor de } \\
\text { agua das } \\
\text { sementes }\end{array}$} \\
\hline & \multicolumn{2}{|c|}{ Temperat. Umid.Relativa } & & & & \\
\hline & $\left({ }^{\circ} \mathrm{C}\right)$ & $(\%)$ & & $\left({ }^{\circ} \mathrm{C}\right)$ & $\left({ }^{\circ} \mathrm{C}\right)$ & \\
\hline 0 & 26,7 & 64 & - & 26 & 26 & 16,5 \\
\hline 30 & 25,0 & 68 & 71 & 32 & 23 & 15,9 \\
\hline 60 & 25,4 & 67 & 70 & 32 & 25 & 15,5 \\
\hline 90 & 23,3 & 70 & 70 & 34 & 29 & 15,2 \\
\hline 120 & 22.8 & 68 & 71 & 34 & 30 & 15,0 \\
\hline 150 & 22.8 & 70 & 71 & 35 & 31 & 14,8 \\
\hline 180 & 22,3 & 68 & 70 & 35 & 31 & 14,6 \\
\hline 210 & 21.7 & 66 & 72 & 34 & 30 & 14,4 \\
\hline 240 & 20.6 & 70 & 71 & 35 & 31 & 14,2 \\
\hline .270 & 29.2 & 69 & 70 & 35 & 30 & 13,8 \\
\hline 310 & 20.0 & 70 & 68 & 35 & 31 & 13,2 \\
\hline Média & 24.7 & 69 & 70 & - & - & - \\
\hline
\end{tabular}

A temperatura média do ar de secagem alcançou $90^{\circ} \mathrm{C}$, ao passo que a temperatura média do ar ambiente foi de $25^{\circ} \mathrm{C}$ (Tabela 3). Com a elevação da temperatura média do ar de $25^{\circ} \mathrm{C}$ para $90^{\circ} \mathrm{C}$, a umidade relativa do ar sofreu uma redução de $71 \%$ para $3 \%$, conforme gráfico psicrométrico (LASSERAN. 1978) e desta maneira, aumentou, de forma acentuada, sua capacidade de retenção de água.

A massa de sementes na câmara de secagem atingiu a temperatura máxima de $41^{\circ} \mathrm{C}$, enquanto que na saída do secador chegou a $37^{\circ} \mathrm{C}$, mantendo uma diferença de temperatura de $4^{\circ} \mathrm{C}$ entre estes pontos; esta diferença foi igualmente manifestada na secagem à temperatura do ar de $70^{\circ} \mathrm{C}$.

A Figura 3 expressa, através de uma equação de primeiro grau, a curva de secagem de sementes de milho, empregando o método intermitente à temperatura do ar de $90^{\circ} \mathrm{C}$, representativa de $96,95 \%$ da variação. Para teores de água entre 15,9 e $13,0 \%$, a velocidade de secagem conservou-se constante em $0,7 \% / \mathrm{h}$.

Comparando-se as velocidades de secagem, nas três temperaturas do ar empregadas, observa-se que a 80 e $90^{\circ} \mathrm{C}$, seus valores foram, respectivamente, 27 e $52 \%$ maiores do que a da temperatura de $70^{\circ} \mathrm{C}$.

O tempo necessário para a massa de sementes realizar uma passagem completa no sistema secadorelevador foi de 90 minutos e, à temperatura do ar de $90^{\circ} \mathrm{C}$, a duração total da secagem foi de 210 minutos. Levando em consideração a relação de intermitência de $1: 1,6$, é possível verificar que as sementes estiveram expostas ao ar aquecido durante 82 minutos e passaram cerca de 2,3 vezes pelo sistema de secagem. Sob a temperatura do ar de $80^{\circ} \mathrm{C}$, o tempo de secagem foi de 240 minutos $e$ as sementes passaram aproximadamente 2,7 vezes pelo sistema, permanencendo 94 minutos na câmara de secagem. Entretanto, à temperatura de $70^{\circ} \mathrm{C}$, o tempo de secagem foi de 300 minutos, ou seja, 25 e $43 \%$ maior do que a 80 e $90^{\circ} \mathrm{C}$, respectivamente, e as sementes deram 3,3 passagens no sistema secadorelevador, ficando 117 minutos expostas ao ar aquecido.

Nas três temperaturas empregadas, a redução do teor de água em funçăo do tempo foi constante, possiveimente porque a velocidade de deslocamento interno da água para a superfíciee da semente tenha 
Tabela 2 - Dados referentes d̀s determinações realizadas durante a secagem das sementes de milho empregando ar de secagem à temperatura de $80^{\circ} \mathrm{C}$.

\begin{tabular}{|c|c|c|c|c|c|c|}
\hline \multirow{2}{*}{$\begin{array}{l}\text { Tempo de } \\
\text { Secagem }\end{array}$} & \multicolumn{2}{|c|}{ Ambiente } & \multirow{2}{*}{$\begin{array}{l}\text { Temp. de } \\
\text { ar de } \\
\text { secagem }\end{array}$} & \multicolumn{2}{|c|}{ Temperatura de sementes } & \multirow{2}{*}{$\begin{array}{l}\text { Teor de } \\
\text { agua das } \\
\text { sementes }\end{array}$} \\
\hline & Temperatura & Umid.Rel. & & CâmaraSecagem & Saída Secador & \\
\hline (min) & $\left({ }^{\circ} \mathrm{C}\right)$ & (\%) & $\left({ }^{\circ} \mathrm{C}\right)$ & ( $\left.{ }^{\circ} \mathrm{C}\right)$ & $\left({ }^{\circ} \mathrm{C}\right)$ & $(\%)$ \\
\hline $\mathbf{0}$ & 26,7 & 66 & - & 26 & 26 & 15,8 \\
\hline 30 & 26,2 & 66 & 78 & 32 & 27 & 15,5 \\
\hline 60 & 28,0 & 65 & 83 & 37 & 30 & 15,1 \\
\hline 90 & 24,4 & 72 & 82 & 38 & 31 & 14,8 \\
\hline 120 & 23,3 & 74 & 80 & 38 & 31 & 14,6 \\
\hline 150 & 24,1 & 75 & 79 & 39 & 32 & 14,5 \\
\hline 180 & 23,8 & 76 & 80 & 38 & 31 & 14,1 \\
\hline 210 & 23,4 & 76 & 78 & 39 & 32 & 13,6 \\
\hline 240 & 23,5 & 77 & 79 & 39 & 32 & 13,1 \\
\hline Média & 24,6 & 72 & 80 & - & - & - \\
\hline
\end{tabular}

sido igual ou superior à velocidade de remoção do vapor d'água pelo ar, conforme HALL (1980), FOUST et al. (1982) e LUZ (1986). Outra hipótese provável é a de que, embora a velocidade de transporte interno tenha sido menor do que a velocidade de evaporação, ocorreu igualmente, durante o período de respouso, transferência de água do interior para a periferia da semente, aumentando a disponibilidade de água superficial a ser evaporada.

A velocidade de secagem depende da temperatura, umidade relativa e fluxo do ar, do tempo de exposição a estas condiçōes, dos teores de água inicial e final (LASSERAN, 1978), de caracteristicas da semente e das propriedades da interface semente-ar (SODHA et al., 1987). Os teores de água inicial e final da semente, a umidade relativa e o fluxo de ar, assim como o tempo de exposição ao ar aquecido em cada passagem pelo sistema secador-elevador, não apresentaram diferenças marcantes nas três secagens. Entretanto, a temperatura do ar $\mathrm{e}$, em consequência, a temperatura da massa de sementes, foram consideravelmente diferentes, de tal forma que quanto mais elevada a temperatura, maior foi a velocidade de

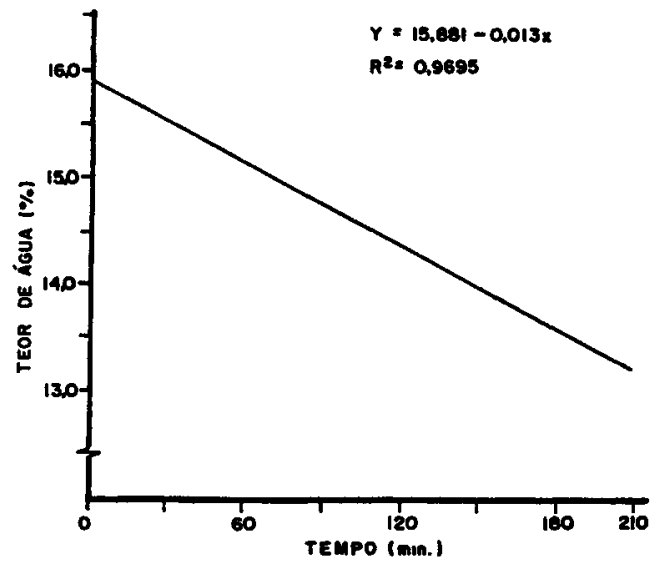

Figura 3 - Curva de secagem representando o comportamento do teor de água das sementes de milho em função do tempo. Secagem a temperatura do ar de $90^{\circ} \mathrm{C}$. 
Tabela 3 - Dados referentes às determinações realizadas durante a secagem das sementes de milho empregando ar de secagem à temperatura de $90^{\circ} \mathrm{C}$.

\begin{tabular}{|c|c|c|c|c|c|c|}
\hline \multirow{2}{*}{$\begin{array}{l}\text { Tempo de } \\
\text { Secagem }\end{array}$} & \multicolumn{2}{|c|}{ Ambiente } & \multirow{2}{*}{$\begin{array}{l}\text { Temp. do } \\
\text { ar de } \\
\text { secagem }\end{array}$} & \multicolumn{2}{|c|}{ Temperatura de sementes } & \multirow{2}{*}{$\begin{array}{l}\text { Teor de } \\
\text { água das } \\
\text { sementes }\end{array}$} \\
\hline & Temperatura & Umid.Relat. & & CâmaraSecagem & Saída Secador & \\
\hline$(\min )$ & $\left({ }^{\circ} \mathrm{C}\right)$ & (\%) & $\left({ }^{\circ} \mathrm{C}\right)$ & $\left({ }^{\circ} \mathrm{C}\right)$ & $\left({ }^{\circ} \mathrm{C}\right)$ & $(\%)$ \\
\hline 0 & 22,8 & 76 & - & 23 & 23 & 15,9 \\
\hline 30 & 23,4 & 74 & 86 & 34 & 28 & 15,5 \\
\hline 60 & 24,2 & 74 & 92 & 37 & 32 & 15,0 \\
\hline 90 & 25,0 & 72 & 94 & 38 & 33 & 14,7 \\
\hline 120 & 25,3 & 70 & 90 & 39 & 35 & 14,4 \\
\hline 150 & 25,6 & 68 & 92 & 40 & 36 & 14,1 \\
\hline 180 & 26,5 & 68 & 88 & 41 & 37 & 13,5 \\
\hline 210 & 27,4 & 66 & 90 & 41 & 37 & 13,0 \\
\hline Média & 25,0 & 71 & 90 & - & - & - \\
\hline
\end{tabular}

secagem e menor o tempo total de exposição ao ar aquecido.

As velocidades de secagem de 0,$52 ; 0,66 \mathrm{e}$ $0,79 \% / \mathrm{h}$, obtidas no presente trabalho, evidenciam que as sementes de milho apresentam secagem lenta concordando com a afirmação de KREYGER (1973), comparativamente às sementes de arroz, que alcançam 1,6 a $2,0 \% / \mathrm{h}$, ao utilizar no método intermitente, temperaturas do ar de $70^{\circ} \mathrm{C}(\mathrm{LUZ}, 1986)$ e às sementes de azevém (Lolium multiflorum L.) que pode chegar a $2,0 \% / \mathrm{h}$, empregando ar a $80^{\circ} \mathrm{C}$ (BOUNOUS, 1986).

A relação entre o teor de água da semente e o tempo de secagem foi representada por funções lineares nas três temperaturas empregadas. Esta ocorrência vem ao encontro dos resultados alcançados por LUZ (1986) e BOUNOUS (1986) ao utilizarem, também, o método intermitente. Este comportamento, entretanto, contraria as afirmações de KREYGER (1973), BROOKER et al. (1974), HALL (1980), FOUST et al., (1982) e SODHA et al., (1987). Segundo estes autores, as sementes apresentam periodo de secagem a velocidade constante, muito cuirto ou inexistente, sendo a curva característica de secagem, representada por uma combinação de segmentos curvilineos.
Contudo, algumas considerações devem ser feitas, visando auxiliar a compreensão da discordância anteriormente mencionada:

- a curva característica de secagem, descrita pelos autores, foi obtida, experimentalmente, na secagem estacionária e contínua de um produto, em camada de pequena espessura, sob condições constantes de temperatura, umidade relativa e velocidade do ar:

- as curvas de secagem, obtidas no presente trabalho, têm validade para teores de água entre $16,5 \mathrm{e}$ $13,0 \%$, representando um segmento intermediário da curva característica, não expressando o comportamento da redução da água da semente em função do tempo, para teores além de $16,5 \%$ e aquém de $13,0 \%$;

- a taxa de remoção do vapor d'água pelo ar, não foi, provavelmente, afetada de forma acentuada, por limitações na taxa de transporte interno de água, devido ã intermitência; dessa forma, o teor de água decresceu à velocidade constante, dentro do intervalo estudado.

Levando em conta que uma secagem rápida aumenta a possibilidade de fissuras internas e superficiais na semente, causadas pela retração das camadas externas não acompanhada pelas internas, conforme TOLEDO \& MARCOS FILHO (1977), para 
as sementes de milho, que apresentam baixa velocidade de secagem, o método intermitente pode se constituir numa alternativa viável, uma vez que, durante o período de repouso, ocorre uma redução nos gradientes de umidade e temperatura, minimizando os possíveis danos têrmicos.

$\mathrm{Na}$ secagem intermitente, em razão do arrefecimento existente durante o período de repouso, podem ser utilizadas altas temperaturas do ar, sem que a temperatura das sementes atinja níveis prejudiciais à sua qualidade. A temperatura da massa de sementes conserva-se abaixo da temperatura do ar de secagem, devido ao resfriamento que estas sofrem quando não estão sob a ação do ar aquecido, e à maior evaporação de água por unidade de tempo efetivo de secagem. Em decorrência deste último fato, as sementes perdem calor com maior intensidade, mantendo-se à temperaturas mais baixas.

O tempo total necessário para que o teor de água das sementes fosse reduzido de $16,0 \%$ para $13,0 \%$, ao ser utilizado ar aquecido a $70^{\circ} \mathrm{C}, 80^{\circ} \mathrm{C}$ e $90^{\circ} \mathrm{C}$, foi respectivamente, de 270 minutos, 240 minmutos e 210 minutos. $\mathrm{Na}$ secagem de sementes de milho em secador intermitente, as temperaturas do ar empregadas não excedem, em geral, $70^{\circ} \mathrm{C}$. A utilização de temperaturas do ar mais elevadas permite reduzir de forma apreciável o tempo de secagem, aumentando, desta forma, a capacidade operacional do secador.

A massa de sementes atingiu temperaturas máximas de $35^{\circ} \mathrm{C}, 39^{\circ} \mathrm{C}$ e $41^{\circ} \mathrm{C}$, quando foi empregado, no secador intermitente, ar aquecido a $70^{\circ} \mathrm{C}, 80^{\circ} \mathrm{C}$ e $90^{\circ} \mathrm{C}$, respectivamente. Esta constatação está de acordo com os resultados alcançados por LUZ (1986), na secagem de sementes de arroz pelo método intermitente, utilizando temperaturas do ar de $70^{\circ} \mathrm{C}$, onde verificou que a massa de sementes atingiu a temperatura máxima de $42^{\circ} \mathrm{C}$, sem causar efeitos imediatos e latentes sobre a qualidade fisiológica.

Não obstante a utilização de temperaturas de ar de $70^{\circ} \mathrm{C}, 80^{\circ} \mathrm{C}$ e $90^{\circ} \mathrm{C}$, a temperatura da massa de sementes não alcançou níveis prejudiciais à qualidade físiológica das sementes, conforme o relatado por HARRINGTON (1972) e TOLEDO \& MARCOS FILHO (1977).

\section{CONCLUSÕES}

Considerando temperaturas do ar de secagem de 70,80 e $90^{\circ} \mathrm{C}$ e reduções do teor de água de $16,5 \%$ para $13,0 \%$, concluiu-se: a) as curvas de secagem de sementes de milho, na secagem intermitente, podem ser representadas por funções lineares.

b) o aumento da velocidade de secagem e a redução do tempo total de exposição das sementes ao ar aquecido podem ser obtidos pela elevação da temperatura do ar de secagem.

\section{REFERÊNCIAS BIBLIOGRÁFICAS}

BOUNOUS, E.B. Comparação de métodos de secagem em sementes de azevém anual (Lolium multiflorum L.). Pelotas,RS, UFP, 1986. 109p. Dissertação de Mestrado.

BRASIL, Ministério da Agricultura. Secretaria Nacional de Defesa Agropecuária. Regras para análise de sementes. Brasilia, 1980. 188p.

BROOKER, D.B.; BAKKER-ARKEMA, F.W.; HALL, C.W. Drying cereal grains.Westport, AVI Publishing, 1974. 265p.

CROSS, H.Z. A selection procedure for ear dryingrates in maize. Euphytica, Dordrecht, 34:409-18, 1985.

FORTES, M. A non-equilibrium thermodynamics approach to transport phenomena in capillaryporous media with special reference to drying of grains and foods. West Lafayette, Purdue University, 1978. 172p. Tese de Ph.D.

FOUST, A.S.; WENZEL, L.A.; CLUMP, C.W.; MAUS, L.; ANDERSEN, L.B. Princípios das operaçōes unitárias. Rio de Janeiro, Guanabara Dois, 1982. 670p.

HALL, C.W. Drying and storage of agricultural crops. Westport, AVI Publishing, 1980. 382p.

HARRINGTON, J.F. Seed storage and longevity. In: KOZLOWSKI, T.T. Seed biology. New York Academic Press, 1972. v.3, p.145-245.

HERTER, U. Effect of drying on corn seed quality. Ames, lowa State University, 1987. 173p. Tese de Ph.D. 
KREYGER, J. Practical observations on the drying of seed. Seed Science and Technology. Zurich, 1:645-70, 1973.

LASSERAN, J.C. Princípios gerais de secagem. Revista Brasileira de Armazenamento, Viçosa, 3(3):17-45, 1978.

LUZ, C.A.S. Secagem de sementes de arroz em secador intermitente lento. Pelotas, RS. 1986. 103p. Dissertação de Mestrado.

PURDY, J.L. \& CRANE, P.L. Inheritance of drying rate in mature corn (Zea mays L.). Crop Science, Madison, 7:294-7, 1967.

SODHA, M.S.; BANSAL, N.K.; KUMAR, A.; BANSAL, P.K.; MALIK, M.A.S. Solar crop drying. Boca Raton, CRC Press, 1987. v.1. $141 \mathrm{p}$.

TOLEDO, F.F. \& MARCOS FILHO, J. Manual das sementes: tecnologia da produção. São Paulo, Agronômica Ceres, 1977. 224p.

TOTH, A. \& SULLER, A. Examination of maize; seed drying process. International Agrophysics, Budapest, 3(4):343-52, 1987. 